Int. J. Electrochem. Sci., 12 (2017) 3020 - 3029

\title{
Development of an Electrochemical Approach for Proline Content Detection in Winter Wheat
}

\author{
Lijie Liu ${ }^{1, *}$, Dongxiang Zhang ${ }^{1}$, Zhongmin Jin ${ }^{1}$, Zhenzhu Zhang ${ }^{1}$, Shanshan Li ${ }^{1}$ and Jing Cang ${ }^{2, *}$ \\ ${ }^{1}$ College of Life Science and Agriculture Forestry, Qiqihar University, Qiqihaer, Helongjiang, P.R. \\ China \\ ${ }^{2}$ College of Life Science, Northeast Agricultural University, P.R. China \\ *E-mail: cangjing321@163.com
}

doi: $10.20964 / 2017.04 .52$

Received: 24 January 2017 / Accepted: 3 March 2017 / Published: 12 March 2017

\begin{abstract}
A novel glassy carbon electrode (GCE) modified with polymerized film of acid chrome blue $\mathrm{K}$ (ACBK) was successfully synthesized by electropolymerization. The electrochemically synthesized poly-ACBK film was characterized by attenuated total reflection (ATR)-FTIR, voltammetric methods and electrochemical impedance spectroscopy (EIS) as well. The as-prepared poly-ACBK/GCE displayed excellent electrocatalytic activity towards the oxidations of proline in comparision with bare GCE. The effect of various experimental parameters such as electrolyte and thickness of poly-ACBK on the oxidation performance of proline on poly-ACBK/GCE electrode was studied. The proposed sensor exhibited linear response in the proline concentration ranging from 1 to $1500 \mu \mathrm{M}$ with the detection limit of $0.25 \mu \mathrm{M}$. In addition, the proposed proline sensor exhibited outstanding performance in the determination of proline in winter wheat samples as well owing to its remarkable stability and repeatability.
\end{abstract}

Keywords: Proline; Electrochemical sensor; Poly-ACBK; Winter wheat; Determination

\section{FULL TEXT}

(C) 2017 The Authors. Published by ESG (www.electrochemsci.org). This article is an open access article distributed under the terms and conditions of the Creative Commons Attribution license (http://creativecommons.org/licenses/by/4.0/). 